\title{
Relation between Endothelial Protein C Receptor Gene Polymorphisms rs867186 and rs9574, and the Risk of Deep Vein Thrombosis in Sudanese
}

\author{
Hytham Ahmed Abuagla1, Awad Omer Ahmed ${ }^{2}$, Ahmed Kamal Bolad ${ }^{3}$, \\ Khalid Mohamed Adam ${ }^{1}$ \\ ${ }^{1}$ Department of Medical Lab Science, Faculty of Applied Medical Science, Bisha University, Bisha, KSA \\ ${ }^{2}$ Department of Hematology, Royal Care International Hospital, Khartoum, Sudan \\ ${ }^{3}$ Graduate College, Alneelain University, Khartoum, Sudan \\ Email: hythamabuaagla@hotmail.com
}

Received 24 December 2015; accepted 7 January 2016; published 11 January 2016

Copyright (C) 2016 by authors and OALib.

This work is licensed under the Creative Commons Attribution International License (CC BY). http://creativecommons.org/licenses/by/4.0/

(c) (i) Open Access

\begin{abstract}
Background: Deep venous thrombosis (DVT) can lead to a serious fatal pulmonary embolism. Many genetic risk factors may predispose to DVT; one of these is the mutation in the PROCR gene responsible for the production of endothelial protein $C$ receptor (EPCR), which plays an important role in activation of protein C (PC). The objective of the present study was to examine the association between the rs867186 and rs9574 polymorphism in the PROCR gene and the occurrence of DVT in Sudanese individuals. Methods: A total of 100 Sudanese DVT patients and 100 apparently healthy individuals were recruited for this study. Ethylene diamine tetraacetic acie (EDTA)-anticoagulated blood samples were collected from all participants. Genomic DNA was extracted and PROCR gene product was amplified by a standard ploymerase chain reaction (PCR) reaction. PCR products were sequenced to identify PROCR gene polymorphisms. Results: The frequency of mutated allele of rs867186 was significantly higher in the DVT patient $(41 \%)$ than in healthy control (21\%). The presence of mutated allele of rs867486 increases the risk of DVT 3 folds. There was no significant difference in the frequency of mutated allele of rs9574 polymorphism between the DVT patients and the healthy control subjects. Further, it does not show an increase in the risk of DVT. The adjustment of gender, ethnic group, and body mass index (BMI) does not change the significance of each single nucleotide polymorphism (SNP) as a risk factor for DVT. Conclusion: It can be concluded that Sudanese individuals carrying the mutated allele rs867186 polymorphism were at risk to develop DVT, while the mutated allele of rs9574 polymorphism is not a risk factor for DVT in Sudanese individuals.
\end{abstract}

\section{Keywords}

Deep Vein Thrombosis, Pulmonary Embolism, EPCR, rs867186, rs9574, Sudanese

How to cite this paper: Abuagla, H.A., Ahmed, A.O., Bolad, A.K. and Adam, K.M. (2016) Relation between Endothelial Protein C Receptor Gene Polymorphisms rs867186 and rs9574, and the Risk of Deep Vein Thrombosis in Sudanese. Open Access Library Journal, 3: e2310. http://dx.doi.org/10.4236/oalib.1102310 


\section{Introduction}

DVT is the formation of blood clots (thrombi) in deep veins, associated with a number of risk factors [1] and preventable morbidity and mortality [1]. An accurate diagnosis of DVT is extremely important to prevent potentially fatal acute complication of pulmonary embolism (PE) and long-term complications of postphlebitic syndrome and pulmonary hypertension [1]. Many genetic and acquired factors impede the natural anticoagulation process which in turn results in a hypercoagulable state and eventually thrombus formation. Protein $\mathrm{C}$ system is one of the most important naturally occurring anticoagulants affected by these factors, activated by thrombinthrombomodulin complex [2]. This activation is enhanced by an endothelial cell surface receptor, EPCR [3]. Centelles M.N. et al. [4] reported that blocking EPCR can accelerate thrombus development. The gene encodes for this receptor; PROCR gene located in chromosome 20q11.2 and comprised of four exons and 3 introns. The first exon encodes for the 5' untranslated region (UTR) and signal peptides; the fourth exon encodes an additional 10 residues of extracellular domain, the transmembrane domain, the cytoplasmic tail and 3'UTR, while the second and third exons encode for most of the extracellular domain [5]. Many studies [6]-[8] reported an association between the presence of rs867186 polymorphism in exon 4 of PROCR gene and risk of venous thrombosis, while other studies [9] [10] concluded an association between a 3’UTR polymorphism (rs9574), and decreased risk of thrombosis. A lack of association between the latter polymorphism and the risk of venous thrombosis was also reported [11]-[14]. The aim of this study is to examine the association between the rs867186 and rs9574 polymorphisms and DVT in Sudanese patients.

\section{Materials and Methods}

In a case control study carried out during the period between January 2013 and May 2015, a sample of 200 participants were recruited, 100 Doppler ultrasonographically confirmed DVT patients (45\% male and 55\% female) with age ranged from 18 to 59 years, attended different Khartoum state hospitals, designated as cases group. Patients with hematological diseases, history of DVT, liver and kidney dysfunctions, infections, autoimmune diseases, tumors, or those receiving thrombolytic treatment or anticoagulant treatment were excluded. While the control group comprised of 100 apparently healthy individuals (58\% male and $42 \%$ female) with age ranged from 17 to 55 years. All controls were the co-patients of the DVT patient to ensure the maximum homogeneity between the cases and controls. Participants with history of thrombosis were excluded from the control group.

The study was approved by the ethical committee of research department, Ministry of Heath, Khartoum state, Sudan, and an informed written consent was also obtained from all participants. The study results were used for research purpose only, and were made available for all participants.

\subsection{Blood Sample Collection}

Five ml venous blood were drawn from all participants into an EDTA blood container and stored at $-80^{\circ} \mathrm{C}$ until further processing.

\subsection{DNA Extraction and Genotyping Analysis}

The genomic DNA was extracted from the blood samples using modified salting out method [14]. Specified regions in PROCR gene were amplified using conventional thermal cycler with the following set of in silico designed primers; F-5'taaacgggtccctttcctct3' and R-5'ctcccctccctcaaatcttc3' for exon 4 (384 bp). Two single nucleotide polymorphisms, (rs867186); located in exon 4 with ancestral allele A and reference SNP allele G, and (rs9574); located in the 3' UTR with ancestral allele C and reference SNP allele G, were selected in silico, the selection of these SNPs based on minor allele frequency (MAF > 5\%) and validation status using Ensemble and single nucleotide polymorphism database (dbSNP) of national center for biotechnology information (NCBI) tools. The cycling conditions for polymerase chain reaction (PCR) were 30 cycles of denaturation $\left(95^{\circ} \mathrm{C}\right.$ for 30 seconds), annealing $\left(54^{\circ} \mathrm{C}-66^{\circ} \mathrm{C}\right.$ for 50 seconds) and extension $\left(72^{\circ} \mathrm{C}\right.$ for 60 seconds). A preheating step at 
$95^{\circ} \mathrm{C}$ for 5 minutes and a final extension step for 7 minutes at $72^{\circ} \mathrm{C}$ were also carried out. The PCR products were stored at $4^{\circ} \mathrm{C}$. Prior to sequence determination of each DNA fragment with advanced sequencing technique, the size of each fragment was ascertained with agarose gel electrophoresis, later all PCR products were sent for purification and DNA sequencing to Macrogen Inc., Seoul, Republic of South Korea.

\subsection{Data Analysis}

The sequencing data were analyzed using the basic local alignment search tool (BLAST) program of NCBI, and SPSS 16. Level of significance for the statistical tests was set at 0.05 .

\section{Results}

The demographic data of this study showed that cases group comprised of $45 \%$ males and $55 \%$ females with age ranged from 15 to 59 years, 26\% Nilo-Saharan, 60\% Afro-Asiatic, and 14\% Congo-Niger, and 10\% underweight, $72 \%$ normal weight, $12 \%$ overweight and $6 \%$ obese. While the control group were $58 \%$ males, $42 \%$ females, with age ranged from 17 to 55 years. 22\% Nilo-Saharan, 56\% Afro-Asiatic, and 22\% Congo-Niger and, $4 \%$ underweight, 70\% normal weight, 20\% over weight, and 6\% obese, as showed in Table 1.

In this study the frequency of the mutated allele of rs867186 polymorphism was significantly high in DVT patients than in healthy individuals $(P$ value $<0.05)$. The allele frequency of this polymorphism was $21 \%$ in control group and $41 \%$ in the case group for the mutated allele, while the normal allele was $79 \%$ and $59 \%$, in the two study groups respectively as shown in Table 2 . On the other hand no statistically significant difference was observed in the allele frequency of the rs9574 polymorphism between DVT patients and healthy individuals ( $P$ value $>0.05$ ). The frequency of the mutated allele of rs9574 were $23 \%$ as for controls and 18 for cases, and for normal allele were $77 \%$ and $82 \%$, respectively shown in Table 3.

The results of regression analysis showed that the mutated allele of rs867186 significantly increases the risk of DVT $(\mathrm{OR}=2.614$; 95\% CI, 1.400 - 4.883) $(P$ value $<0.05)$ as shown in Table 4. Further adjustment of the

Table 1. Demographic data for DVT patients and healthy controls.

\begin{tabular}{|c|c|c|c|}
\hline & & DVT Patients & Healthy Controls \\
\hline \multirow{2}{*}{ Gender } & Male $\%$ & 45 & 58 \\
\hline & Female \% & 55 & 42 \\
\hline \multirow{4}{*}{ BMI } & Under Weight \% & 10 & 4 \\
\hline & Normal Weight \% & 72 & 70 \\
\hline & Over Weight \% & 12 & 20 \\
\hline & Obese \% & 6 & 6 \\
\hline \multirow{3}{*}{ Ethnic Groups } & Nilo-Saharan \% & 26 & 22 \\
\hline & Afro-Asiatic \% & 60 & 56 \\
\hline & Congo-Niger \% & 14 & 22 \\
\hline
\end{tabular}

Table 2. Cross-tabulation between rs867186 and the study groups.

\begin{tabular}{|c|c|c|c|c|c|c|}
\hline & & & \multicolumn{2}{|c|}{ rs867186 } & \multirow{2}{*}{ Total } & \multirow{2}{*}{ Pearson Chi-Square ( $P$ value) } \\
\hline & & & Normal & Mutated & & \\
\hline \multirow{7}{*}{ Study groups } & & Count & 79 & 21 & 100 & \multirow{7}{*}{0.002} \\
\hline & Control & & & & & \\
\hline & & $\%$ & $79.0 \%$ & $21.0 \%$ & $100 \%$ & \\
\hline & \multirow{4}{*}{ Case } & & & & & \\
\hline & & Count & 59 & 41 & 100 & \\
\hline & & & & & & \\
\hline & & $\%$ & $59.0 \%$ & $41.0 \%$ & $100 \%$ & \\
\hline
\end{tabular}


regression model to gender, ethnicity and BMI showed slight increase of risk of DVT with the mutated allele $(\mathrm{OR}=2.817$; 95\% CI, $1.467-5.410)(P$ value $<0.05)$ as shown in Table 5.

Single nucleotide polymorphism rs9574 does not show statistically significant effect as a risk factor for DVT ( $P$ value $>0.05$ ), as shown in Table 6. The lack of rs9574 effect as risk factor has not changed after addition of other potential risk factors to the regression model as shown in Table 7 (Figures 1-3).

Table 3. Cross-tabulation between rs9574 and the study groups.

\begin{tabular}{|c|c|c|c|c|c|c|}
\hline & & & \multicolumn{2}{|c|}{ rs9574 } & \multirow{2}{*}{ Total } & \multirow{2}{*}{ Pearson Chi-Square ( $P$ value) } \\
\hline & & & Normal & Mutated & & \\
\hline \multirow{4}{*}{ Study groups } & & Count & 77 & 23 & 100 & \multirow{4}{*}{0.381} \\
\hline & Control & $\%$ & $77 \%$ & $23 \%$ & $100 \%$ & \\
\hline & \multirow{2}{*}{ Case } & Count & 82 & 18 & 100 & \\
\hline & & $\%$ & $82 \%$ & $18.0 \%$ & $100 \%$ & \\
\hline
\end{tabular}

Table 4. Odd ratio of rs867186 as a risk factor for DVT.

\begin{tabular}{|c|c|c|c|c|c|}
\hline & & \multirow{2}{*}{$P$ value } & \multirow{2}{*}{$\operatorname{Exp}(B)$} & \multicolumn{2}{|c|}{$95.0 \%$ CI for $\mathrm{EXP}(\mathrm{B})$} \\
\hline & & & & Lower & Upper \\
\hline \multirow{2}{*}{ Step 1} & rs867186 & 0.003 & 2.614 & 1.400 & 4.883 \\
\hline & Constant & 0.090 & 0.747 & & \\
\hline
\end{tabular}

Table 5. Odd ratio of rs867186 and confounders as a risk factor for DVT.

\begin{tabular}{|c|c|c|c|c|c|}
\hline & & \multirow{2}{*}{$P$ value } & \multirow{2}{*}{$\operatorname{Exp}(B)$} & \multicolumn{2}{|c|}{$95.0 \%$ CI for $\mathrm{EXP}(\mathrm{B})$} \\
\hline & & & & Lower & Upper \\
\hline \multirow{10}{*}{ Step 1} & rs867186 & 0.002 & 2.817 & 1.467 & 5.410 \\
\hline & Female & 0.061 & 1.792 & 0.974 & 3.299 \\
\hline & Nilo-Saharan & 0.341 & & & \\
\hline & Afro-Asiatic & 0.781 & 0.905 & 0.446 & 1.835 \\
\hline & Congo-Niger & 0.171 & 0.512 & 0.197 & 1.335 \\
\hline & Under Weight & 0.371 & & & \\
\hline & Normal Weight & 0.129 & 0.377 & 0.107 & 1.329 \\
\hline & Over Weight & 0.077 & 0.286 & 0.071 & 1.148 \\
\hline & Obese & 0.255 & 0.372 & 0.068 & 2.037 \\
\hline & Constant & 0.444 & 1.715 & & \\
\hline
\end{tabular}

Table 6. Odd ratio of rs9574 as a risk factor for DVT.

\begin{tabular}{|c|c|c|c|c|c|}
\hline & & \multirow{2}{*}{$P$ value } & \multirow{2}{*}{$\operatorname{Exp}(B)$} & \multicolumn{2}{|c|}{$95.0 \% \mathrm{CI}$ for $\mathrm{EXP}(\mathrm{B})$} \\
\hline & & & & Lower & Upper \\
\hline \multirow{2}{*}{ Step 1} & rs9574 & 0.382 & 0.735 & 0.368 & 1.466 \\
\hline & Constant & 0.692 & 1.065 & & \\
\hline
\end{tabular}




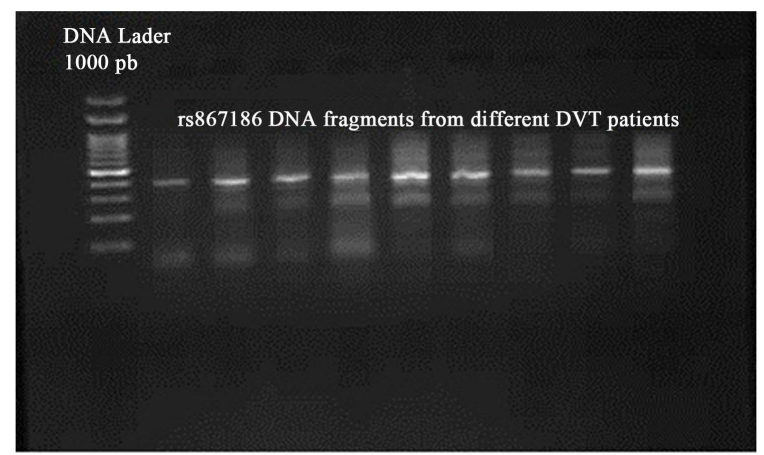

Figure 1. Results of gel electrophoresis for DVT patients.
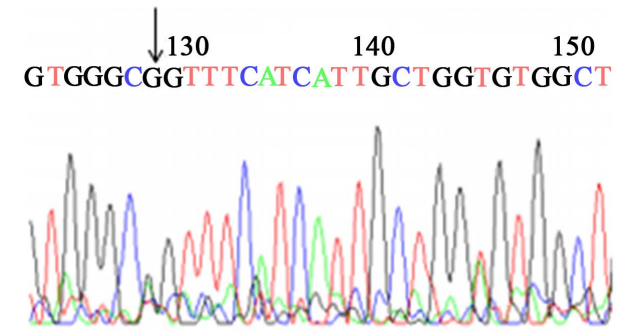

Figure 2. DNA sequence of the mutated allele of rs867186.

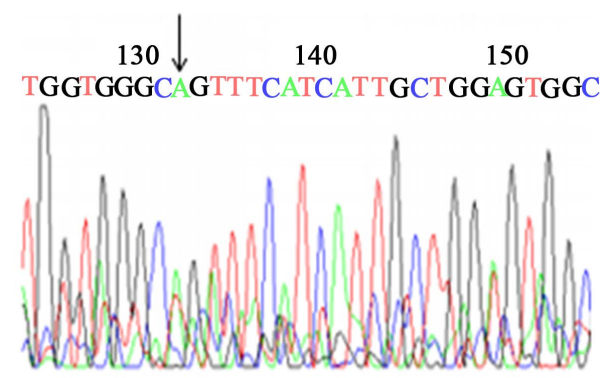

Figure 3. DNA sequence of the normal allele of rs867186.

Table 7. Odd ratio of rs9574 and confounders as a risk factor for DVT.

\begin{tabular}{|c|c|c|c|c|c|}
\hline & & \multirow{2}{*}{$P$ value } & \multirow{2}{*}{$\operatorname{Exp}(B)$} & \multicolumn{2}{|c|}{$95.0 \%$ CI for $\mathrm{EXP}(\mathrm{B})$} \\
\hline & & & & Lower & Upper \\
\hline \multirow{10}{*}{ Step 1} & rs9574 & 0.492 & 0.778 & 0.380 & 1.591 \\
\hline & Female & 0.108 & 1.624 & 0.899 & 2.934 \\
\hline & Nilo-Saharan & 0.331 & & & \\
\hline & Afro-Asiatic & 0.904 & 0.958 & 0.478 & 1.920 \\
\hline & Congo-Niger & 0.185 & 0.530 & 0.207 & 1.355 \\
\hline & Under Weight & 0.373 & & & \\
\hline & Normal Weight & 0.165 & 0.419 & 0.122 & 1.432 \\
\hline & Over Weight & 0.078 & 0.293 & 0.075 & 1.147 \\
\hline & Obese & 0.328 & 0.435 & 0.082 & 2.307 \\
\hline & Constant & 0.231 & 2.274 & & \\
\hline
\end{tabular}




\section{Discussion}

A reliable accurate diagnosis of DVT is extremely important to prevent potentially fatal acute complications such as pulmonary embolism (PE) and the long-term complications of post-phlebitic syndrome and pulmonary hypertension. It is also important to avoid unjustified therapy with anticoagulants associated with high risk of bleeding in patients misdiagnosed with the condition. In the human body the anticoagulation process is influenced by a number of genetic and acquired factors that may lead to hypercoagulable states and eventually thrombus formation. The PC system is one of the key anticoagulants produced by the human body, activated by thrombin-thrombomodulin complex and an endothelial surface receptor known as EPCR [6]. Therefore, a decrease in the activity of EPCR as a result of mutation in the gene coding for this receptor will emphatically alter PC activation process.

The demographic data of the DVT group in this study showed a younger mean age 35.89 years which compares favorably with 45 years in Uganda [15] and 42 years in Senegal [16], this young age can be attributed to the young demographic structure of the Sudanese population, and to some extend to the lack of a reliable and precise tool for age determination other than the reliance on the patient's own estimation. Another contributing factor could be the limited travel and access of old patients to healthcare due to socio-cultural constrains.

The results of this study indicated that the frequency of the mutated allele of rs867186 polymorphism is higher among DVT patients than in healthy control group. This finding is consistent with that reported by many studies [9] [11] [17] [18]. While no difference was observed in the allele frequency of rs9574 polymorphism between the DVT patients and the healthy individuals.

The high frequency of mutated allele of rs867186 in the patients group is indicative of possible role in the etiology or pathogenesis of the disease, Navarro, S et al. [19], and Karabiyik A et al. [11] reported that mutated allele of rs867186 increases the risk of VTE by approximately two-folds in the carriers of prothrombin 20210A allele, in another study Saposnik, B et al. [9] reported an association between rs867186 and elevated levels of plasma sEPCR as well as the risk of DVT. The possible role of rs867186 polymorphism as a risk factor for DVT was also suggested by Yin, G et al. [17] and Chen, X et al. [20] in two separate studies carried out to explore the distribution of allele frequency of rs867186 among both thrombotic patients and healthy individuals, they reported high allele frequency of the SNP in the patients group as compared to their healthy counterparts. A strong supportive evidence of the role of this SNP in the disease comes from the conclusion of meta-analysis of observational studies conducted by Jessica Dennis et al. [21] who reported a significant association between the SNP and the disease. In contrast to our finding, Uitte de WS et al. [10], Yamagishi K et al. [22], and Medina P et al. [10] [22] [23] reported no association between rs867186 polymorphism and the risk of DVT. The relation between the rs867186 single nucleotide polymorphism and deep venous thrombosis can be explained by the fact that rs867186 polymorphism has been documented to cause conformational change in EPCR as a result of substitution of serine amino acid in position 219 with glycine leading to increased shedding of this receptor as sEPCR [24] which has high affinity towards PC and activated protein C (APC), a consequent binding of sEPCR to APC interferes with its anticoagulant action this will ultimately result in a hypercoagulable state and thrombosis. The relation between rs867186 and DTV can also be explained under the light of the findings of study conducted by Saposnik B et al. [25] who concluded that cells carry the mutated allele of rs867186 polymorphism produce an abnormal mRNA that encodes a truncated protein lacks the transmembrane and intracellular domains which gets secreted directly into the plasma as sEPCR.

The findings of the present study are suggestive to the lack of significant synergistic or antagonistic effect of gender, ethnicity, and BMI on the potential risk of rs867186 for thrombosis.

On the other hand no relation was observed between rs9574 polymorphism and the risk of DVT, this goes in concordance with the reports by Medina P et al. [23] [26] and Saposnik B et al. [9], while Espana F et al. [27] reported that this polymorphism reduces the risk of VTE by 3 folds and attributed this protective effect to its association with high level of APC.

\section{Conclusion}

In conclusion the findings of the current study suggest that Sudanese carriers of the mutated allele of rs867186 polymorphism are at high risk to develop DVT, while rs9574 polymorphism plays a neither risky nor protective role for DVT in Sudanese individuals. 


\section{Acknowledgements}

We are highly appreciated to staff of haematology and molecular biology departments, faculty of medical laboratory science, Alneelain University and the staff of Khartoum State Hospitals.

\section{References}

[1] Douketis, J.D. (2015) Deep Vein Thrombosis (DVT).

http://www.merckmanuals.com/home/heart-and-blood-vessel-disorders/venous-disorders/deep-vein-thrombosis-dvt

[2] Kesieme, E., Kesieme, C., Jebbin, N., Irekpita, E. and Dongo, A. (2011) Deep Vein Thrombosis: A Clinical Review. Journal of Blood Medicine, 2, 59-69. http://dx.doi.org/10.2147/JBM.S19009

[3] Sirlak, M., Inan, M.B., Cetintas, D. and Ozcinar, E. (2012) Risk Factors of Deep Vein Thrombosis. Cheng, G., Ed., InTech, 1. http://www.intechopen.com/books/deep-vein-thrombosis/risk-factors-of-deep-vein-thrombosis

[4] Rosendaal, F.R. and Reitsma, P.H. (2009) Genetics of Venous Thrombosis. Journal of Thrombosis and Haemostasis, 7, 301-304. http://dx.doi.org/10.1111/j.1538-7836.2009.03394.x

[5] Wong, P. and Baglin, T. (2012) Epidemiology, Risk Factors and Sequelae of Venous Thromboembolism. Phlebology, 27, 2-11. http://dx.doi.org/10.1258/phleb.2012.012S31

[6] Fukudome, K. and Esmon, C.T. (1994) Identification, Cloning, and Regulation of a Novel Endothelial Cell Protein C/ Activated Protein C Receptor. Journal of Biological Chemistry, 269, 26486-26491.

[7] Kurosawa, S., Stearns-Kurosawa, D.J., Hidari, N. and Esmon, C.T. (1997) Identification of Functional Endothelial Protein C Receptor in Human Plasma. Journal of Clinical Investigation, 100, 411-418. http://dx.doi.org/10.1172/JCI119548

[8] Raife, T.J. and Lentz, S.R. (2005) The Benefits of Excess EPCR. Thrombosis and Haemostasis, 3, 1349-1350. http://dx.doi.org/10.1111/j.1538-7836.2005.01462.x

[9] Saposnik, B., Reny, J.L., Gaussem, P., Emmerich, J., Aiach, M. and Gandrille, S. (2004) A Haplotype of the EPCR Gene Is Associated with Increased Plasma Levels of sEPCR and Is a Candidate Risk Factor for Thrombosis. Blood, 103, 1311-1318. http://dx.doi.org/10.1182/blood-2003-07-2520

[10] Uitte de, W.S., Van, M.V., Rosendaal, F.R., Vos, H.L., De Visser, M.C. and Bertina, R.M. (2004) Haplotypes of the EPCR Gene, Plasma sEPCR Levels and the Risk of Deep Venous Thrombosis. Journal of Thrombosis and Haemostasis, 2, 1305-1310. http://dx.doi.org/10.1046/j.1538-7836.2004.00855.X

[11] Karabiyik, A., Yilmaz, E., Egin, Y. and Akar, N. (2012) The Effects of Endothelial Protein C Receptor Gene Polymorphisms on the Plasma sEPCR Level in Venous Thrombosis Patients. Turkish Journal of Hematology, 29, 55-62.

[12] Ducros, E., Mirshahi, S.S., Faussat, A.M., Mirshahi, P., Dimicoli, S., Tang, R., et al. (2012) Soluble Endothelial Protein C Receptor (sEPCR) Is Likely a Biomarker of Cancer-Associated Hypercoagulability in Human Hematologic Malignancies. Cancer Medicine, 1, 261-267. http://dx.doi.org/10.1002/cam4.11

[13] Abd-Elghfaar, A.A., Ismail, M.M., Farweez, B.A. and Elmasry, R.F. (2013) Influence of Soluble Endothelial Protein C Receptor (sEPCR) on Hypercoagulable State of Haemodialysis Patients. International Journal of Science and Research, 4, 1123-1128.

[14] Miller, S.A., Dykes, D.D. and Polesky, H.F. (1988) A Simple Salting out Procedure for Extracting DNA from Human Nucleated Cells. Nucleic Acids Research, 16, 1215. http://dx.doi.org/10.1093/nar/16.3.1215

[15] Muleledhu, A.L., Galukande, M., Makobore, P., Mwambu, T., Ameda, F. and Kiguli-Malwadde, E. (2013) Deep Venous Thrombosis after Major Abdominal Surgery in a Ugandan Hospital: A Prospective Study. International Journal of Emergency Medicine, 6, 43. http://dx.doi.org/10.1186/1865-1380-6-43

[16] Fall, A.O.T., Proulle, V., Sall, A., Mbaye, A., Samba Ba, P., Diao, M., et al. (2014) Risk Factors for Thrombosis in an African Population. Clinical Medical Insights: Blood Disorders, 7, 1-6.

[17] Yin, G., Jin, X., Ming, H., Zheng, X. and Zhang, D. (2012) Endothelial Cell Protein C Receptor Gene 6936A/G Polymorphism Is Associated with Venous Thromboembolism. Experimental and Therapeutic Medicine, 3, 989-992.

[18] Chen, X.D., Tian, L., Li, M., Jin, W., Zhang, H.K. and Zheng, C.F. (2011) Relationship between Endothelial Cell Protein C Receptor Gene 6936A/G Polymorphisms and Deep Venous Thrombosis. Chinese Medical Journal, 124, 72-75.

[19] Navarro, S., Medina, P., Mira, Y., Estelles, A., Villa, P., Ferrando, F., et al. (2008) Haplotypes of the EPCR Gene, Prothrombin Levels, and the Risk of Venous Thrombosis in Carriers of the Prothrombin G20210A Mutation. Haematologica, 93, 885-891. http://dx.doi.org/10.3324/haematol.12448

[20] Chen, X.D., Tian, L., Zheng, C.F., Li, M., Jin, W., Wang, X.H., et al. (2010) Relationship between Endothelial Protein C Receptor Gene 6936A/G Polymorphisms and Deep Venous Thrombosis. Chinese Journal of Hematology, 31, 607609. 
[21] Dennis, J., Johnson, C.Y., Adediran, A.S., de Andrade, M., Heit, J.A., Morange, P.E., et al. (2012) The Endothelial Protein C Receptor (PROCR) Ser219Gly Variant and Risk of Common Thrombotic Disorders: A HuGE Review and Meta-Analysis of Evidence from Observational Studies. Blood, 119, 2392-2400. http://dx.doi.org/10.1182/blood-2011-10-383448

[22] Yamagishi, K., Cushman, M., Heckbert, S.R., Tsai, M.Y. and Folsom, A.R. (2009) Lack of Association of Soluble Endothelial Protein C Receptor and PROCR 6936A/G Polymorphism with the Risk of Venous Thromboembolism in a Prospective Study. British Journal of Haematology, 145, 221-226. http://dx.doi.org/10.1111/j.1365-2141.2009.07612.x

[23] Medina, P., Navarro, S., Estelles, A., Vaya, A., Woodhams, B., Mira, Y., et al. (2004) Contribution of Polymorphisms in the Endothelial Protein C Receptor Gene to Soluble Endothelial Protein C Receptor and Circulating Activated Protein C Levels, and Thrombotic Risk. Thrombosis and Haemostasis, 91, 905-911. http://dx.doi.org/10.1160/th03-10-0657

[24] Qu, D., Wang, Y., Song, Y., Esmon, N.L. and Esmon, C.T. (2006) The Ser219-->Gly Dimorphism of the Endothelial Protein C Receptor Contributes to the Higher Soluble Protein Levels Observed in Individuals with the A3 Haplotype. Journal of Thrombosis and Haemostasis, 4, 229-235. http://dx.doi.org/10.1111/j.1538-7836.2005.01676.x

[25] Saposnik, B., Lesteven, E., Lokajczyk, A., Esmon, C.T., Aiach, M. and Gandrille, S. (2008) Alternative mRNA Is Favored by the A3 Haplotype of the EPCR Gene PROCR and Generates a Novel Soluble form of EPCR in Plasma. Blood, 111, 3442-3451. http://dx.doi.org/10.1182/blood-2007-08-104968

[26] Medina, P., Navarro, S., Estelles, A., Vaya, A., Bertina, R.M. and Espana, F. (2005) Influence of the 4600A/G and 4678G/C Polymorphisms in the Endothelial Protein C Receptor (EPCR) Gene on the Risk of Venous Thromboembolism in Carriers of Factor V Leiden. Thrombosis and Haemostasis, 94, 389-394.

[27] Espana, F., Medina, P., Navarro, S., Estelles, A. and Aznar, J. (2002) Inherited Abnormalities in the Protein C Activation Pathway. Pathophysiology of Haemostasis and Thrombosis, 32, 241-244. http://dx.doi.org/10.1159/000073573

\section{Abbreviations}

\begin{tabular}{cc}
\hline APC & Activated protein C \\
BLAST & Basic local alignment search tool \\
BMI & Body mass index \\
dbSNP & Single nucleotide polymorphism data base \\
DNA & Deoxyribonucleic acid \\
DVT & Deep vein (venous) thrombosis \\
EDTA & Ethylene diamine tetra-acetic acid \\
EPCR & Endothelial protein C receptor \\
MAF & Minor allele frequency \\
NCBI & National center for biotechnology information \\
OR & Odd ratio \\
PC & Protein C \\
PCR & Polymerase chain reaction \\
PE & Pulmonary embolism \\
SNP & Single nucleotide polymorphism \\
SPSS & Statistical package for social science \\
UTR & \\
\hline
\end{tabular}

